\title{
Computational identification and annotation of salt stress responsive genes in Solanum melongena $\mathrm{L}$.
}

\author{
Bibi Sadia $^{1 *}$, Iftekhar Ahmed Baloch ${ }^{2}$, Zahoor Ahmed Bazai ${ }^{2}$, Wajia \\ Noor $^{1}$ and Shehnaz Shair Qambrani ${ }^{1}$ \\ 1. Department of Botany, SBK Women's University Quetta-Pakistan \\ 2. Department of Botany, University of Balochistan, Quetta-Pakistan \\ *Corresponding author's email: zarmal.gul@gmail.com \\ Citation \\ Bibi Sadia, Iftekhar Ahmed Baloch, Zahoor Ahmed Bazai, Wajia Noor and Shehnaz Shair Qambrani. \\ Computational identification and annotation of salt stress responsive genes in Solanum melongena L. Pure and \\ Applied Biology. Vol. 9, Issue 1, pp132-139. http://dx.doi.org/10.19045/bspab.2020.90016
}

\begin{tabular}{llll}
\hline \hline Received: 15/05/2019 & Revised: 15/08/2019 & Accepted: 03/09/2019 & Online First: 18/09/2019
\end{tabular}

\section{Abstract}

Solanum melongena L. (Eggplant) is an important plant of family Solanaceae. It possesses pronounced nutritional value and is a rich source of minerals and vitamins. As a medicinal plant it is used for the cure of numerous diseases. Nasunin, a main component in anthocyanin pigment of eggplant shows free radical scavenging and iron chelating activities. Salinity is the main abiotic stress in agriculture all over the world. The effects of salinity on plants include ion imbalance, oxidative harm, hyperosmotic stress, reactive oxygen species production, fall of leaf water potential, reduced stomatal conductance and inhibition of photosynthesis. This study is an attempt to identify and annotate the potential orthologues of salt stress responsive genes in eggplant by using a variety of bioinformatics tools (BLASTn, ORF finder, $\mathrm{CD}$ search and Clustal W). Briefly a total of 20 well annotated, salt responsive stress genes (CSD1,HVA22A, RCI3, SOS4, CDPK1, P5CS1, SAT32, STZ, SOS1, SZF1, ORYSJ, SODM_ORYSJ, G3PC1_ORYSJ, Os PIP1-3, OSISAP1, OsBADH1, Q40710_ORYSJ, ACA5_ORYSJ, SALT_ORYSJ, SAP11_ORYSJ ), 10 each from Arabidopsis thaliana (The model dicot plant) and Oryza sativa (The model monocot plant) were selected through literature survey and their ORF sequences were subjected to BLASTn against the publically available 98,089 ESTs of eggplant. Consequently all 20 genes were predicted in eggplant and classified as highly similar (showing upto 90\% query coverage), somewhat similar (showing upto 60\% query coverage) and less similar (showing upto 30\% query coverage) orthologues. Furthermore the salt stress responsive conserved domains were identified in 18 genes by using CD search tool. Phylogenetic trees were also constructed for some of the identified genes by using Clustal W. EST based identification of these genes confirms the expression of these genes in eggplant which may be helpful to comprehend its acclimation processes.

Keywords: Conserved domains; Salt stress; Solanum melongena Introduction diabetes, arthritis, asthma, bronchitis [2], Eggplant (Solanum melongena L.) is important vegetable as it is an affluent source of minerals and vitamins [1]. Grown typically for its fruit, eggplant is designated for the treatment of several ailments like toothache, cardiac debility, neuralgias etc [3]. Nasunin and Pheophytin pigments of eggplant have free radical hunting and antimutagenic activity [4]. Salt stress is one of the main abiotic stresses faced by plants. 
Plants identify the stress signals and pass them to the cellular apparatus and then the adaptation is fulfilled by the regulation of gene expression [5]. Expressed sequence tags (ESTs) produced from cDNA libraries are the best source to find out stress associated genes [6]. Bioinformatics approaches are the renowned ways of research for nucleic acid sequence analysis to discover new genes [7]. The current research is planned at examination of salt stress genes in $S$. melongena by using a variety of bioinformatics tools like BLAST (Basic Local Alignment Search Tool), ORF finder (Open Reading Frame), CD search (Conserved Domain) and Clustal W. Identification of salt stress responsive genes will be a good input for understanding the salt stress responsive method in eggplant.

Materials and methods

A total of 20 well annotated, salt stress responsive genes (CSD1,HVA22A, RCI3, SOS4, CDPK1, P5CS1, SAT32, STZ, SOS1, SZF1, ORYSJ, SODM_ORYSJ, G3PC1_ORYSJ, Os PIP1-3, OSISAP1, OsBADH1, Q40710_ORYSJ, ACA5_ORYSJ, SALT_ORYSJ, SAP11_ORYSJ) were selected from the model plants i.e. Arabidopsis thaliana and Oryza sativa (10 genes of each) through literature survey [8-21] and an attempt was made to identify the potential orthologues of these genes in eggplant. The main steps of the methodology are discussed below.

Fetching of the sequences of the selected model genes and their ORFs

Gene Sequences of model plants were fetched using NCBI (National Centre for Biotechnology and Information) and saved in FASTA format. To get the exact coding region of the genes, FASTA sequence of each gene was subjected to ORF finder available at NCBI. Longest reading frames for each of the genes were predicted. The nucleotide sequences of the longest ORFs were then used to find their orthologues in eggplant.

\section{Homology search}

BLAST is one of the most excellent tools for homology search [22]. The available 98,089 ESTs (dbEST release 130101, 01 January 2013) of eggplant were computationally screened to search 20 genes. To find out existence of gene, the ORF sequences of every model plant gene were subjected to BLASTn against $S$. melongena. The best matched EST (on the basis of query coverage and percentage identity) were selected and their sequences were saved in FASTA format. The selected ESTs were categorized as highly similar (showing upto $90 \%$ query coverage), somewhat similar (showing upto 60\% query coverage) and less similar (showing upto $30 \%$ query coverage) orthologues.

\section{Finding conserved domains}

Conserved domain database (CDD) [23] is another important tool of NCBI. Model plant genes and best matched ESTs of $S$. melongena. were subjected to CDD to detect the occurrence and position of conserved domains which perform their fucnction in salinity. With this method conserved domains of the model plant genes were compared with the conserved domains of best matched ESTs of $S$. melongena.

\section{Phylogenetic analysis of genes}

Advanced version of Clustal-w called MUSCLE, was used to conduct phylogenetic analysis of some genes. Cladograms were constructed for some of the predicted genes in eggplant and other plants.

\section{Results}

\section{Identification of new conserved salt stress genes in eggplant}

All the selected (20) salt stress responsive genes were Identified in $S$. melongena through insilico analysis of 98,089 ESTs of $S$. melongena. Homology search of the selected model genes in $S$. melongena 
resulted up to $99 \%$ query coverage. The identified homologous genes were classified as highly similar, somewhat similar and less similar i.e showing up to $90 \%, 60 \%$ and $30 \%$ query coverage respectively. Seven genes (CSD1, HVA22A, RCI3, ORYSJ, SODM_ORYSJ, G3PC1_ORYSJ and Os PIP1-3) were highly similar, five genes (SOS4, CDPK1, P5CS1, OSISAP1 and OsBADH1) were somewhat similar and eight genes (SAT32, STZ, SOS1, SZF1, Q40710_ORYSJ, ACA5_ORYSJ, SALT_ORYSJ and SAP11_ORYSJ ) were less similar (Figure1 \& 2).

Identification of conserved domains in predicted genes

The conserved domains examination of selected plant genes in $S$. melongena demonstrated that on 18 genes similar conserved domains were also present in $S$. melongena irrespective of query coverage and identity, excluding two genes (SALT_ORYSJ and SAP11_ORYSJ). (Table $1 \& 2$ ).

\section{Phylogenetic analysis of genes}

Eight of the salt stress responsive genes (CSD1, HVA22A, SODM_ORYSJ, SODM_ORYSJ, RCI3, SOS4, ORYSJ and G3PC1_ORYSJ) were randomly selected for phylogenetic analysis. Cladograms were constructed by comparing three homolog genes, i.e one from selected model plant, second from $S$. melongena (subject plant) and third one from dicot (in case of $A$. thaliana) and monocot (in case of $O$. sativa). The results are shown in (Figures 3-10).

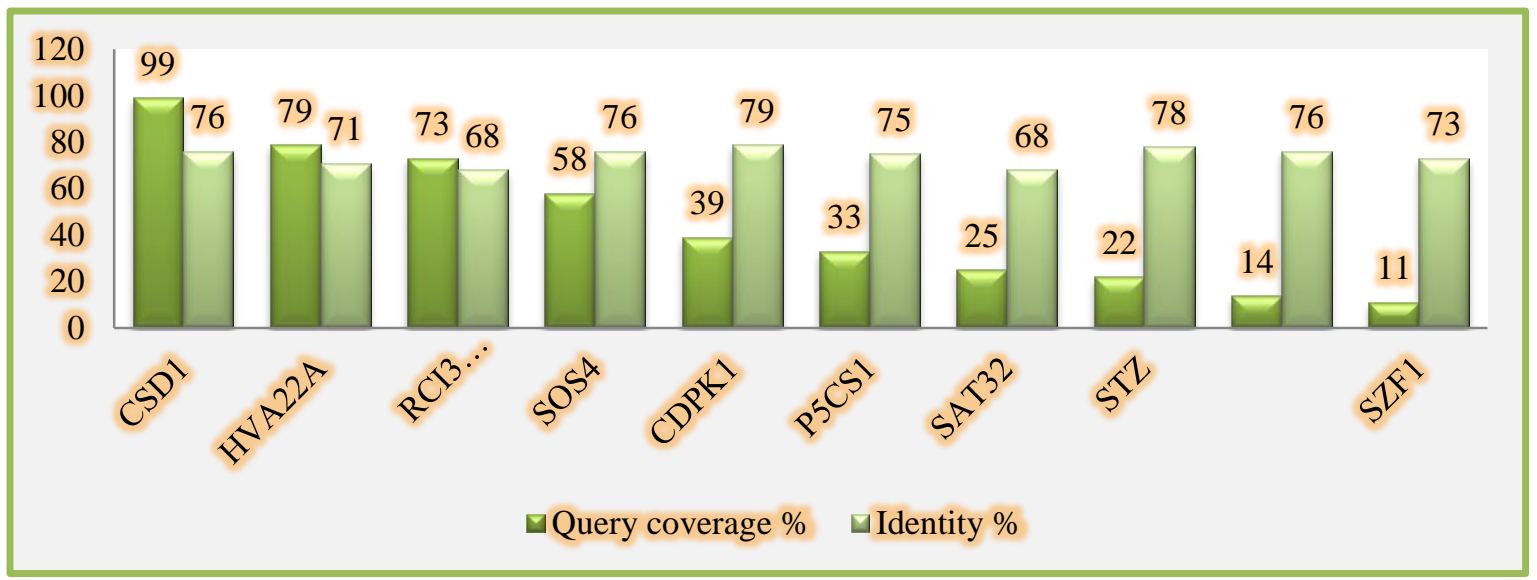

Figure 1. Homology of S. melongena with the Model genes from A.thaliana

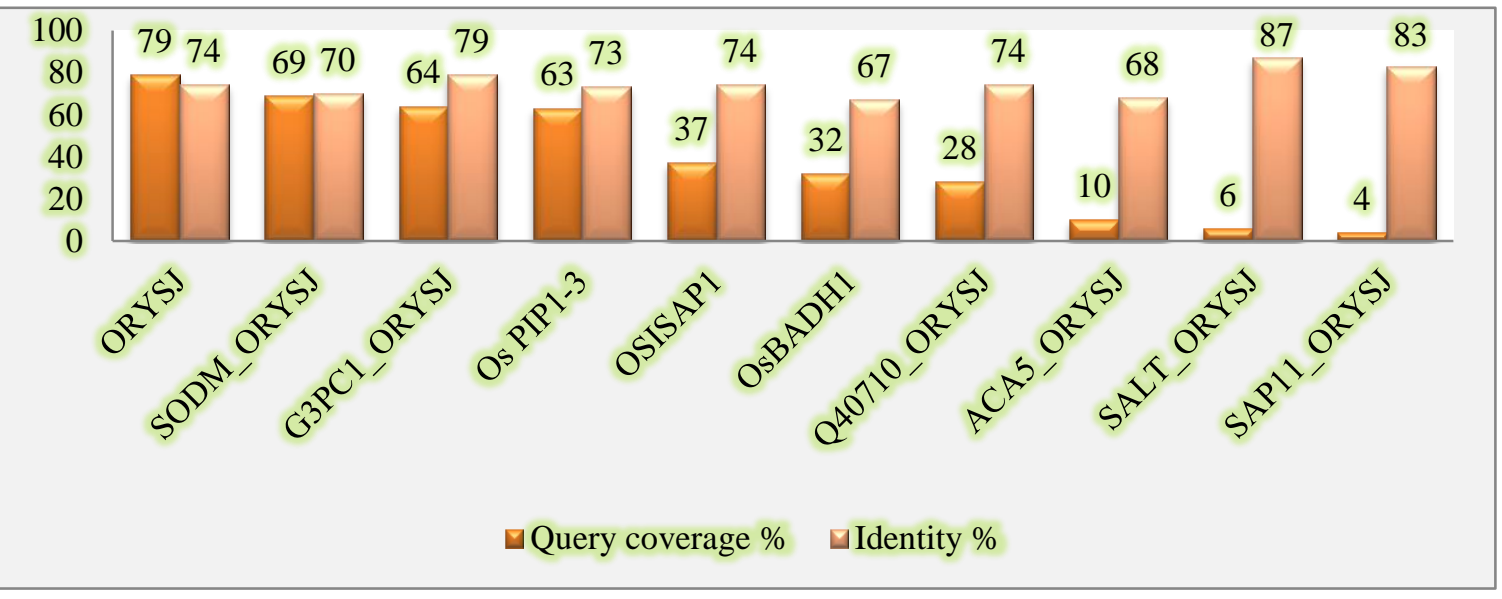

Figure 2. Homology of $S$. melongena with the model genes from $O$. sativa 
Table 1. Comparison of existence and type of conserved domain families between $A$. thaliana and S. melongena

\begin{tabular}{|c|c|c|c|}
\hline \multirow{2}{*}{ S } & \multirow{2}{*}{ Gene } & name & \multicolumn{2}{|c|}{ Conserved domain family } \\
\cline { 3 - 4 } & CSD1 & Cu_Zn superoxide dismutase & S. melongena \\
\hline 1 & super-family & Cu_Zn superoxide dismutase super-family \\
\hline 2 & HVA22A & TB2_DP1_HVA22 super family & TB2_DP1_HVA22 super family \\
\hline 3 & RCI3 & plant peroxidase like super family & plant peroxidase like super family \\
\hline 4 & SOS4 & ribokinase_pfkB_like super family & ribokinase_pfkB_like super family \\
\hline 5 & CDPK1 & PKc_like super family & PKc_like super family \\
\hline 6 & P5CS1 & AAK_super family & AAK_super family \\
\hline 7 & SAT32 & IFRD super family & IFRD super family \\
\hline 8 & STZ & zf-C2H2_6 super family & zf-C2H2_6 super family \\
\hline 9 & SOS1 & Asp-Al_Ex super family & Asp-A1_Ex super family \\
\hline 10 & SZF1 & ZnF_C3H1 super family & ZnF_C3H1 super family \\
\hline
\end{tabular}

Table 2. Comparison of existence and type of conserved domain families between $O$. sativa and $S$. melongena

\begin{tabular}{|c|c|c|c|}
\hline \multirow{2}{*}{ S \# } & \multirow{2}{*}{ Gene name } & \multicolumn{2}{|c|}{ Conserved domain family } \\
\cline { 3 - 4 } & ORYSJ & $\begin{array}{c}\text { O. sativa } \\
\text { S. melongena }\end{array}$ \\
\hline 1 & SODM_ORYSJ & $\begin{array}{c}\text { Sod_Fe_C and Sod_Fe_N } \\
\text { super families }\end{array}$ & $\begin{array}{c}\text { Sod_Fe_C and Sod_Fe_N super } \\
\text { families }\end{array}$ \\
\hline 3 & G3PC1_ORYSJ & $\begin{array}{c}\text { Gp_dh_C and Gp_dh_N super } \\
\text { families }\end{array}$ & $\begin{array}{c}\text { Gp_dh_C and Gp_dh_N super } \\
\text { families }\end{array}$ \\
\hline 4 & Os PIP1-3 & MIP super family & MIP super family \\
\hline 5 & OSISAP1 & $\begin{array}{c}\text { ZnF_AN1 and zf-A20 super } \\
\text { families }\end{array}$ & ZnF_AN1 and zf-A20 super families \\
\hline 6 & OsBADH1 & ALDH-SF super family & ALDH-SF super family \\
\hline 7 & Q40710_ORYSJ & $\begin{array}{c}\text { Glyco_tranf_GTA_type super } \\
\text { family }\end{array}$ & Glyco_tranf_GTA_type super family \\
\hline 8 & ACA5_ORYSJ & $\begin{array}{c}\text { CaATP_NAI and } \\
\text { Cation_ATPase_N super } \\
\text { families }\end{array}$ & $\begin{array}{c}\text { CaATP_NAI and Cation_ATPase_N } \\
\text { super families }\end{array}$ \\
\hline 9 & SALT_ORYSJ & Jacalin_like super family & thioredoxin_like super family \\
\hline 10 & SAP11_ORYSJ & $\begin{array}{c}\text { TT_ORF1,ZnF_AN1, zf-A20 } \\
\text { like super families }\end{array}$ & \begin{tabular}{c} 
AdoMet_MTases super family \\
\hline
\end{tabular}
\end{tabular}

Figure 3. Cladogram for CSD1 gene from showing closeness of S.melongena with $C$. arabica as compared to A.thaliana 
Figure 4. Cladogram for HVA22A gene showing closeness of A. thaliana with S.melongena as compared to $S$. lycopersicum

Figure 5. Cladogram for SODM_ORYSJ gene showing closeness of O.sativa with Zea mays as compared to S.melongena

Solanummelongena 0.16537

Arabidopsis 0.16537

Malusdomestica 0.206999

Figure 6. Cladogram for RCI3 gene showing closeness of A.thaliana with S.melongena as compared to Malus domestica

Arabidopsis 0.131952

Solanummelongena 0.0996377

Vitisvinifera 0.0996377

Figure 7. Cladogram for SOS4 gene showing closeness of $V$. vinifera with $S$. melongena as compared to A. thaliana

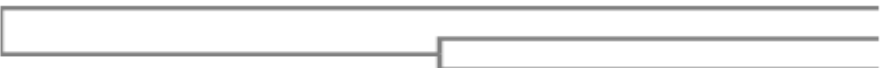

Zeamays 0.150051

Oryzasativa 0.136006

Solanummelongena 0.136006

Figure 8. Cladogram for ORYSJ gene showing closeness of $O$. sativa with S.melongena as compared to Zea mays

Solanummelongena 0.103501

Zeamays 0.0586785

Oryzasativa 0.0586785

Figure 9. Cladogram for G3PC1_ORYSJ gene showing closeness of O.sativa with Zea mays as compared to S.melongena

Solanummelongena 0.159948

Oryza 0.159948

Wolffiaaustraliana 0.195035

Figure 10. Cladogram for OSPIP1-3 gene showing closeness of O.sativa with S.melongena as compared to $W$. australiana

Discussion

Bioinformatics approaches are now commonly used by various researchers to identify stress related genes and proteins in plants [18, 24-26]. Our study resulted in 1 dentification of 20 salt stress responsive 
genes in eggplant. Even though some genes didn't show a high query coverage but presence of the similar conserved domains in reference sequences and $S$. melongena sequences indicates the potential role of these domains during salt stress. EST analysis is a significant tool to identify new conserved genes [27-30]. This approach provides direct evidence for miRNA expression that cannot be inferred from genomic sequence surveys [31]. All of the salt stress genes have been predicted in ESTs of $S$. melongena which is confirmation of their expression. Phylogenetic analysis of the selected genes shows that salt stress genes may be conserved within monocots and dicots and some genes from monocots may be more close to that of dicot genes as compared to the same gene of another monocot and vice versa. All our results are in agreement with the work of other researchers [32-39] and these findings can be valuable to properly comprehend the salt stress tolerance mechanism in eggplant.

\section{Conclusion}

A total of 20 new conserved salt stress genes were computationally predicted in eggplant by data mining of ESTs. Even though all the selected (20) genes didn't show a high query coverage but presence of the similar conserved domains in reference sequences and $S$. melongena sequences indicates the potential role of these domains in salt stress. These findings will be helpful in studying the gene expression profiling of eggplant.

\section{Authors' contributions}

Conceived and designed the experiments: IA Baloch, Performed the experiments: B Sadia, Analyzed the data: B Sadia \& W Noor, Contributed materials/ analysis/ tools: ZA Bazai \& SS Qambrani, Wrote the paper: B Sadia.

\section{References}

1. Abbas W, Ashraf M \& Akram NA (2010). Alleviation of salt-induced adverse effects in eggplant (Solanum melongena L.) by glycinebetaine and sugarbeet extracts. Sci Hort 125(3): 188-195.

2. Magioli C \& Mansur E (2005). Eggplant (Solanum melongena L.): tissue culture, genetic transformation and use as an alternative model plant. Acta Bot Bras 19(1): 139-148.

3. Das M \& Barua N (2013). Pharmacological activities of Solanum melongena Linn.(Brinjal plant). Inter J Green Pharm 7(4): 274.

4. Noda Y, Kneyuki T, Igarashi K, Mori A \& Packer L (2000). Antioxidant activity of nasunin, an anthocyanin in eggplant peels. Toxicol 148(2): 119123.

5. Breyne P \& Zabeau M (2001). Genome-wide expression analysis of plant cell cycle modulated genes. Curr Opin Plant Biol 4(2): 136-142.

6. Sreenivasulu N, Sopory SK \& KaviKishor PB (2007). Deciphering the regulatory mechanisms of abiotic stress tolerance in plants by genomic approaches. Gene 388(1): 1-13.

7. Barozai MYK \& Wahid AH (2012). Insilico identification and characterization of cumulative abiotic stress responding genes in Potato (Solanum tuberosum L.). Pak J Bot 44: 57-69.

8. Hernández JA, Corpas FJ, Gomez M, Río LA \& Sevilla F (1993). Saltinduced oxidative stress mediated by activated oxygen species in pea leaf mitochondria. Physiol Plant 89(1): 103-110.

9. Tsugane K, Kobayashi K, Niwa Y, Ohba Y, Wada K\& Kobayashi H (1999). A recessive Arabidopsis mutant that grows photoautotrophically under 
salt stress shows enhanced active oxygen detoxification. The Plant Cell 11(7): 1195-1206.

10. Shi H, Ishitani M, Kim C \& Zhu JK (2000). The Arabidopsis thaliana salt tolerance gene SOS1 encodes a putative $\mathrm{Na}+/ \mathrm{H}+$ antiporter. Proc Nat Aca Sci 97(12): 6896-6901.

11. Gong Z, Koiwa H, Cushman MA, Ray A, Bufford D, Kore-eda S \& Hasegawa PM (2001). Genes that are uniquely stress regulated in salt overly sensitive (SOS) mutants. Plant Physiol 126(1): 363-375.

12. Shen Q, Chen CN, Brands A, Pan SM $\&$ Tuan-Hua DH (2001). The stressand abscisic acid-induced barley gene HVA22: developmental regulation and homologues in diverse organisms. Plant mol biol 45(3), 327-340.

13. Abrahám E, Rigó G, Székely G, Nagy R, Koncz C \& Szabados L (2003). Light-dependent induction of proline biosynthesis by abscisic acid and salt stress is inhibited by brassinosteroid in Arabidopsis. Plant Mol Biol 51(3): 363-372.

14. Attia H, Arnaud N, Karray N \& Lachaâl M (2008). Long-term effects of mild salt stress on growth, ion accumulation and superoxide dismutase expression of Arabidopsis rosette leaves. Physiol Plant 132(3): 293-305.

15. Mahajan S, Pandey GK \& Tuteja N (2008). Calcium-and salt-stress signaling in plants: shedding light on SOS pathway. Arch Biochem Biophys 471(2): 146-158.

16. Park MY, Chung MS, Koh HS, Lee DJ, Ahn SJ \& Kim CS (2009). Isolation and functional characterization of the Arabidopsis salt-tolerance 32 (AtSAT32) gene associated with salt tolerance and ABA signaling. Physiol Plant 135(4): 426-435.
17. Cui X, Wang T, Chen HS, Busov V \& Wei H (2010). TF-finder: a software package for identifying transcription factors involved in biological processes using microarray data and existing knowledge base. BMC Bioinformatics 11(1): 425.

18. Isokpehi RD, Simmons SS, Cohly HH, Ekunwe SI, Begonia GB \& Ayensu WK (2011). Identification of droughtresponsive universal stress proteins in viridiplantae. Bioinform biol insights 5, 41.

19. Jalali-e-Emam SMS, Alizadeh B, Zaefizadeh M, Zakarya RA \& Khayatnezhad M (2011). Superoxide dismutase (SOD) activity in $\mathrm{NaCl}$ stress in salt-sensitive and salttolerance genotypes of colza (Brassica napus L.). Middle East J Sci Res 7: 711.

20. Abdelkader AF, El-khawas S, El-Din El-Sherif NAS, Hassanein RA, Emam MA \& Hassan RES (2012). Expression of aquaporin gene (Os PIP1-3) in saltstressed rice (Oryzasativa L.) plants pre-treated with the neurotransmitter (dopamine). Plant Omics 5(6): 532.

21. Kumar S, Jaggi M \& Sinha AK (2012). Ectopic overexpression of vacuolar and apoplastic Catharanthus roseus peroxidases confers differential tolerance to salt and dehydration stress in transgenic tobacco. Protoplasma 249(2): 423-432.

22. Altschul SF, Gish W, Miller W, Myers EW \& Lipman DJ (1990). Basic local alignment search tool. $J$ mol biol 215(3), 403-410.

23. Marchler-Bauer A, Lu S, Anderson, Chitsaz BJF, Derbyshire MK, DeWeese-Scott C \& Gwadz M (2011). CDD: a Conserved Domain Database for the functional annotation of proteins. Nucleic Acids Res 39(suppl 1): D225-D229. 
24. Chinnusamy V, Zhu J \& Zhu JK (2007). Cold stress regulation of gene expression in plants. Trends plant sci 12(10): 444-451.

25. Zankari E, Hasman H, Cosentino S, Vestergaard M, Rasmussen S, Lund O \& Larsen MV (2012). Identification of acquired antimicrobial resistance genes. J Antimicrob Chemo 67(11): 2640-2644.

26. Barozai MYK, Shah SQ, Din M Muhammad R (2014). Codon usage bias and RNA secondary structures analysis for virus resistant genes in Arabidopsis thaliana and Oryza sativa. Pure Appl Biol 3(2), 81.

27. Yang GD, Yan $\mathrm{K}, \mathrm{Wu} \mathrm{BJ}$, Wang $\mathrm{YH}$, Gao YX \& Zheng CC (2012). Genomewide analysis of intronic microRNAs in rice and Arabidopsis. $J$ Genet 91(3): 313-324.

28. Barozai MYK \& Husnain T (2012). Identification of biotic and abiotic stress up-regulated ESTs in Gossypium arboreum. Mol Biol Rep 39(2): 10111018.

29. Din M \& Barozai MYK (2014). Profiling microRNAs and their targets in an important fleshy fruit: Tomato (Solanum lycopersicum). Gene 535(2), 198-203.

30. Din M \& Barozai MYK (2014). Profiling and characterization of eggplant (Solanum melongena L.) microRNAs and their targets. Mol Biol Rep 41(2): 889-894.

31. Baloch IA \& Din M (2014). Bioinformatic hunting of microRNAs. Pure Appl Biol 3(2), 72.

32. Jaglo KR, Kleff $\mathrm{S}$, Amundsen KL, Zhang X, Haake V, Zhang JZ \& Thomashow MF (2001). Components of the Arabidopsis Crepeat/dehydration-responsive element binding factor cold-response pathway are conserved inbrassica napus and other plant species. Plant Physiol 127(3): 910-917.

33. Jeong MJ, Park SC \& Byun MO (2001). Improvement of salt tolerance in transgenic potato plants by glyceraldehyde-3 phosphate dehydrogenase gene transfer. Mol Cell 12(2).

34. Brands A \& Ho THD (2002). Function of a plant stress-induced gene, HVA22. Synthetic enhancement screen with its yeast homolog reveals its role in vesicular traffic. Plant Physiol 130(3): 1121-1131.

35. Llorente F, López-Cobollo RM, Catalá R, Martínez-Zapater JM \& Salinas J (2002). A novel cold-inducible gene from Arabidopsis, RCI3, encodes a peroxidase that constitutes a component for stress tolerance. Plant J 32(1): 13-24.

36. Davletova S, Schlauch K, Coutu J \& Mittler (2005). The zinc-finger protein Zat12 plays a central role in reactive oxygen and abiotic stress signaling in Arabidopsis. Plant Physiol 139(2): 847-856.

37. Zhu C, Schraut D, Hartung W \& Schäffner AR (2005). Differential responses of maize MIP genes to salt stress and ABA. J Exp Bot 56(421): 2971-2981.

38. Kulik A, Wawer I, Krzywińska E, Bucholc M \& Dobrowolska G (2011). SnRK2 protein kinases-key regulators of plant response to abiotic stresses. Omics 15(12): 859-872.

39. Gong Y, Rao L \& Yu D (2013). Abiotic stress in plants. Agric Chem 113-152. 